\title{
METHYLPHENIDATE RESPONSE PREDICTION IN ADHD
}

Predictors of response to methylphenidate (MPH) among 47 children with ADHD and mental retardation (MR) were studied at the University of Pittsburgh School of Medicine, and the Western Psychiatric Institute and Clinic, Pittsburgh, PA. A double-blind, placebo-controlled evaluation of two doses of MPH $(0.3$ and $0.6 \mathrm{mg} / \mathrm{kg})$, using Conners Scales, with data collected on weekday and Saturday laboratory classrooms, showed that: 1) higher parent ratings of impulsivity and activity level at baseline were associated with greater gains in weekday classroom dependent measures; 2) higher weekday teacher measures of activity level, impulsivity, inattention, and conduct problems at baseline were related to improvement on Saturday laboratory classroom dependent measures; and 3) male Caucasians of higher socioeconomic status were more likely to show clinical improvements than other subjects. Race and conduct problems had predictive utility specific to children with MR. (Handen BL et al. Prediction of response to methylphenidate among children with ADHD and mental retardation. I Am Acad Child Adolesc Psychiatry October 1994;33:1185-1193). (Reprints: Dr Handen, John Merck Outpatient Program, Western Psychiatric Institute and Clinic, 3811 O'Hara St, Pittsburgh, PA 15213).

COMMENT. The higher the level of hyperactivity and associated inattention in children with ADHD and MR, the greater the beneficial response to methylphenidate. Similar findings have been reported previously in a study of 30 children of normal IQ with ADDH, using actometer measurements of motor activity and a neuropsychological test battery, and also in animals with hyperactivity induced by prefrontal cortical lesions. (Millichap JG. Ann N Y Acad Sci 1973;205:321; Ped Neur Briefs Oct 1987; June 1991).

Children with ADD without hyperactivity or moderate levels of abnormality on Conners Scales are less likely to benefit from stimulant medication than those with ADD and $\mathrm{H}$. Baseline measures of behavior by Conners Scales in ADDH children with MR were more predictive of medication response than the measures obtained in the laboratory classroom.

\section{METHYLPHENIDATE IN ADDH AND EPILEPSY}

The safety of methylphenidate (MPH), $0.3 \mathrm{mg} / \mathrm{kg}$, in 9 boys and 8 girls, ages 6 to 16 years, with ADHD and epilepsy, studied in Jerusalem, Israel, was reported at the Annual Meeting of the Child Neurology Society, Oct 2-8, 1994, in San Francisco, CA. Of 17 patients treated with MPH for 1-month, following a placebo period of 1 -month, 15 children who were seizure-free had no recurrence of seizures, while 2 with 1 to 2 seizures weekly before MPH had a moderate exacerbation of epilepsy. The EEGs showed no "major" changes. AED levels (CBZ and VA) were therapeutic during placebo and MPH periods. ADHD symptoms were benefited by MPH in 12 patients. (Gross-Tsur V et al. Methylphenidate for children with epilepsy and attention deficit hyperactivity disorder. Ann Neurol Sept 1994;36:501 [abstr]).

COMMENT. The authors recommend caution in the use of methylphenidate in ADHD children with an active seizure disorder. The PDR states that: "In the presence of seizures, the drug (MPH) should be discontinued." Based on the present and previous reports there appears to be some justification for trials of MPH in selected patients with ADDH 